\title{
Quality of Life in Oncological Patient at the End of Life
}

\author{
Estevez GM ${ }^{1}$ and Nieves Cuervo GM ${ }^{2 *}$ \\ ${ }^{1}$ Epidemiology specialist, CLINIC gestionar bienestar, Colombia \\ ${ }^{2}$ General Doctor, Regional Hospital Garcia Rovira, Colombia
}

Received: 阱April 21, 2018; Published: 眥 May 17, 2018

*Corresponding author: Giselly Mayerly Nieves Cuervo, General Doctor, Regional Hospital Garcia Rovira, Colombia

\section{Introduction}

Cancer is one of the diseases that have the greatest impact on the quality of life of its patients, either because of the real burden of the disease or because of all the myths involved in its diagnosis. The objective of this article is to evaluate the different factors that affect the quality of life of patients beyond the clinical characteristics of the type of cancer.

\section{Methodology}

A search was made in pubmen with the key words quality of life, spirituality, cancer, terminal cancer. The only exclusion criteria were articles that were more than 5 years old.

\section{Development and Discussion}

It was found that the perception of the quality of life of patients with cancer is related to the fear of death by patients, physical, emotional and psychological changes after diagnosis and treatment [1]. This perception is usually heterogeneous, some patients report being upset by the whole treatment (surgery and chemotherapy) that had happened and others refer that the treatment allows them to give meaning and value to life [1]. Among the main factors associated with quality, it was found that the healthy lifestyle causes a positive impact in terms of the perception of quality, practices such as maintaining a healthy weight, being physically active and on a regular basis, limiting the consumption of unhealthy foods such as red meats and refined carbohydrates can improve clinical outcomes including disease recurrence and survival, and a better quality of life related to health, better physical functioning and less fatigue [2]. Regarding physical activity, objective associations between physical activity of moderate to vigorous intensity and sedentary time with quality of life, physical well being and fatigue are positively associated with higher scores on the quality of life questionnaire and physical and functional well being scores, as well as reduction of fatigue [3]. Maintaining an adequate BMI and adequate physical activity has proved to be a protective intervention [4].
Another important factor is spirituality, since it becomes important as it begins the search for hope and quality of life at the end of life. It is important to say that the spiritual role can be both positive (the event is due to the love or will of god) and negative (the event is due to the wrath of god) that the patient attributes to having cancer [5], however studies have shown that patients consider that the accompaniment in spiritual and religious issues by the doctor can be something that benefits them [6]. Although this point is not a frequent practice in clinical practice and is difficult for health personnel to address, it is a measure of care that favors the trust, tranquility and hope of the patient, in the midst of the adversity of cancer [6]. Since it provides comfort, support and a sense of connection. Spiritual care is paramount to address the spiritual anguish that can develop [7], Even though health personnel are not inclined to address this determining factor, this difficulty may be due to the fact that the medical and nursing staff, although they know the usefulness of spiritual accompaniment, are not sure that it is really beneficial for them. patient or not have the training to perform this type of accompaniment in patients [1].

In the pediatric population it was found that the spiritual care of the child with cancer is not isolated, but is part of a whole. And therapeutic intervention with improved communication favors the child to express their feelings, beliefs, sources of strength and hope and concerns. And the conversations that occur in the creation of a legacy can lead some children to find meaning and purpose in life and death and often help the child in the search for the meaning of terminal cancer [1].

Regarding sexual life, some studies show deterioration in the quality of life and decreased libido, however, patients, especially women, for fear that their husband was absent from home or looking for another woman, continued with sexual activities, in spite of not wanting them, since they feel that they must maintain their commitments as a wife [1]. In the most terminal stages, it was 
found that patients in their last 3 months reported a significantly lower quality of life, a lower functioning and a higher burden of symptoms of fatigue and loss of appetite compared to patients in different periods of time before death. Likewise, the differences for the global quality of life, the cognitive and social functioning was significantly lower [8]. From another point of view, the assessment of the perception of physicians with respect to how cancer diagnosis affects the quality of life of patients was found that doctors have a varied estimate of the harmful impact of cancer treatment, these often underestimated the amount of symptoms associated with cancer treatments [9]. This is probably associated with the reduction of practices in search of improving the quality of life of the patient and not only in search of medical pharmacological treatment of their disease.

\section{Conclusion}

Cancer is a disease that not only affects the biological part of the patient's life, but also their biopsychosocial environment, it is important to take into account the impact of quality of life and begin to motivate and implement those non pharmacological practices that improve the quality of life of patients to provide better care for patients

\section{References}

1. Jassim GA, Whitford DL (2014) Understanding the experiences and quality of life issues of Bahraini women with breast cancer. Soc Sci Med 107: 189-195.
2. Breedveld Peters JJL, Koole JL, Müller Schulte E, Van der Linden BWA, Windhausen C, et al. (2018) Colorectal cancers survivors adherence to lifestyle recommendations and cross sectional associations with health related quality of life. Br J Nutr 16: 1-10.

3. D Silva A, Gardiner PA, Boyle T, Bebb D, Johnson ST, et al. (2018) Associations of objectively assessed physical activity and sedentary time with health related quality of life among lung cancer survivors: A quantile regression approach. Lung Cancer 119: 78-84.

4. Soares Falcetta F, de Araújo Vianna Träsel H, de Almeida FK, Rangel Ribeiro Falcetta M, Falavigna M, et al. (2018) Effects of physical exercise Akter treatment of early breast cancer: systematic review and metaanalysis. Breast Cancer Res Treat.

5. Gall TL, Bilodeau C (2017) "Why me?"-women's use of spiritual causal attributions in making sense of breast cancer. Psychol Health 32(6): 709-727.

6. Phelps AC, Lauderdale KE, Alcorn S, Dillinger J, Balboni MT (2012) Addressing Spirituality Within the Care of Patients at the End of Life: Perspectives of Patients With Advanced Cancer, Oncologists, and Oncology Nurses. J Clin Oncol 30(20): 2538-2544.

7. Petersen CL (2014) Spiritual care of the child with cancer at the end of life: a concept analysis. J Adv Nurs 70(6):1243-1253.

8. Raijmakers $\mathrm{NJH}$, Zijlstra M, van Roij J, Husson O, Oerlemans S, et al. (2018) Health-related quality of life among cancer patients in their last year of life: results from the PROFILES registry. Support Care Cancer.

9. James BC, Aschebrook Kilfoy B, White MG, Apple white MK, Kaplan SP, et al. (2018) Quality of life in thyroid cancer dassessment of physician perceptions. J Surg Res 226: 94-99.

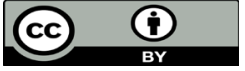

This work is licensed under Creative Commons Attribution 4.0 License

To Submit Your Article Click Here:

Submit Article

DOI: $10.32474 /$ OAJOM.2018.01.000119

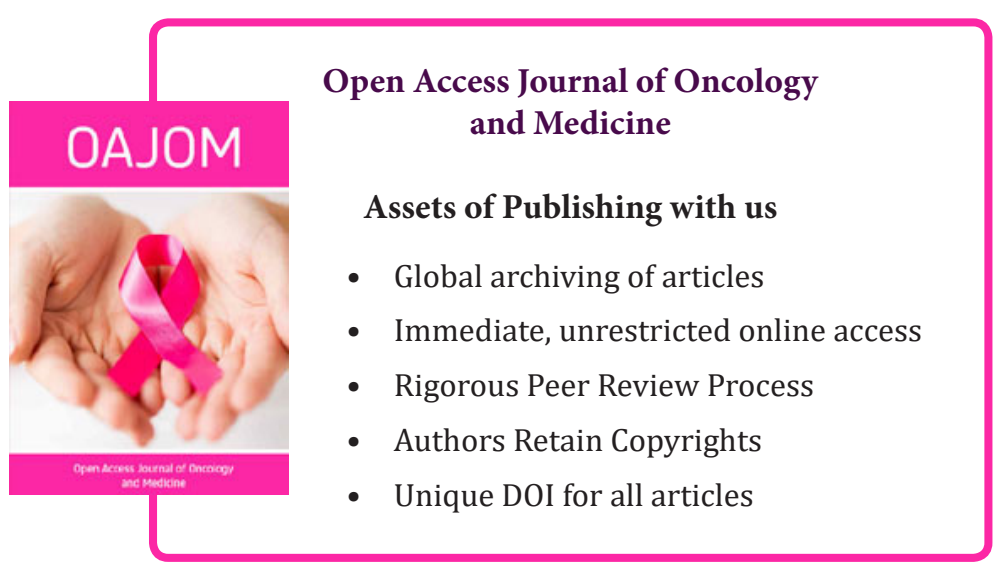

